\title{
Penolakan Dominika Terhadap Pemberlakuan Mata Uang SUCRE
}

Selviana Lailil Maghfiroh ${ }^{1}$

selvianamaghfiroh71@gmail.com

${ }^{1}$ Program Studi Hubungan Internasional, Universitas Muhammadiyah Malang

DOI: $10.22219 /$ sospol.v7i2.10365

\begin{abstract}
This article aims to find out why Dominica made a policy to reject the SUCRE currency. This currency is a regional currency that has been created by ALBA to reduce dependence on the US dollar. ALBA considers SUCRE very important for its members to follow because it will provide economic benefits. This study explains Dominica's decision to reject SUCRE's monetary integration which was analyzed from various internal and external factors based on the theory of The Formulation of Foreign Policy Objectives by Keith R. Legg and James F. Morisson. This article uses a qualitative explanatory method by using secondary data collection techniques in the process. The results show that Dominica's decision not to apply SUCRE as a regional currency is influenced by internal and external factors. These internal factors are: 1) If Dominica adopts the currency, it will be against its membership in the OECS, 2) Dominica's low economic condition makes the country unable to meet the requirements in SUCRE which has an impact on the inability to influence monetary policy against the currency. In addition, external factors are also a consideration for the limited share of the Dominican market at SUCRE.
\end{abstract}

\section{Abstrak}

Artikel ini bertujuan untuk mengetahui mengapa Dominika membuat kebijakan untuk menolak mata uang SUCRE. Mata uang tersebut merupakan sebuah regional currency yang telah dicetuskan oleh ALBA untuk mengurangi ketergantungan terhadap dolar AS. ALBA menganggap SUCRE sangat penting untuk diikuti oleh para anggotanya karena akan memberikan manfaat secara ekonomis. Penelitian ini menjelaskan keputusan Dominika menolak integrasi moneter SUCRE yang dianalisis dari berbagai faktor internal dan eksternal berdasarkan teori The Formulation of Foreign Policy Objectives oleh Keith R. Legg dan James F. Morisson. Artikel ini menggunakan metode eksplanatif kualitatif dengan menggunakan teknik pengumpulan data sekunder dalam prosesnya. Hasilnya menunjukkan bahwa keputusan Dominika tidak menerapkan SUCRE sebagai regional currency dipengaruhi faktor internal dan eksternal. Faktor internal tersebut yaitu: 1) Jika Dominika mengadopsi mata uang tersebut maka akan bertentangan dengan keanggotaannya di OECS, 2) Keadaan ekonomi Dominika yang rendah membuat negara tersebut tidak dapat memenuhi persyaratan di SUCRE yang berdampak pada ketidakleluasaan untuk mempengaruhi kebijakan moneter terhadap mata uang tersebut. Selain itu, faktor eksternal yang juga menjadi pertimbangan terbatasnya pangsa pasar dominika di SUCRE.

\author{
Keywords \\ ALBA, Dominika, Integrasi \\ Moneter, Kebijakan, SUCRE
}

\section{Article History}

Received November 24, 2019

Revised November 24, 2021

Accepted November 26, 2021

Published November 28, 2021

\section{Corresponding Author}

Selviana Lailil Maghfiroh. Prodi

Hubungan Internasional, Universitas Muhammadiyah Malang. Jalan Raya Tlogomas No. 246, Kec. Lowokwaru, Kota Malang, Jawa Timur. 65144.

\section{Pendahuluan}

Munculnya ketidakpuasan banyak negara terhadap tatanan internasional yang saat ini telah didominasi oleh negara super power, membuat negara-negara yang inferior menginginkan adanya perubahan terhadap sistem yang sudah ada. Salah satu contoh dari ketidakpuasan serta ketidakadilan tersebut ialah pengaruh besar yang dimiliki Amerika Serikat (AS) yang dapat membuat dunia internasional menyepakati penetapan dolar Amerika Serikat (USD) sebagai mata 
uang internasional. Hal tersebut membuat keuangan nasional suatu negara termasuk di kawasan Amerika Latin bergantung pada naik turunnya nilai tukar dolar. Sehingga nilai mata uang nasional suatu negara tersebut juga akan bergantung pada kestabilan ekonomi AS.

Hal tersebut membuat negara dunia ketiga menginginkan adanya sebuah perubahan terhadap penggunaan dolar AS, salah satunya yaitu negara-negara di kawasan Amerika Latin yang tergabung dalam sebuah aliansi yang bernama Alianza Bolivariana para los Pueblos de Nuestra América $(A L B A)$ (ALBA, 2014). Negara Amerika Latin dan Karibia yang tergabung dalam ALBA pertama yaitu Venezuela dan Kuba (2004), kemudian diikuti oleh Bolivia (2006), Nikaragua (2007), Dominika (2008), dan kemudian negara lain seperti Ekuador serta negara Karibia lainnya seperti St. Vincent \& The Grenadines dan Antigua \& Barbuda juga turut bergabung kemudian (ALBA Info, 2010). ALBA menginginkan adanya pengurangan penggunaan dolar AS dalam transaksi perdagangan internasional dengan membuat sebuah mata uang bersama bagi negara anggota ALBA yaitu Sistema Unico de Compensacion Regional (SUCRE). Sebelum mata uang tersebut dibentuk, ALBA menciptakan Bank of ALBA. Pada saat diadakannya KT'T Khusus III ALBA di Caracas 26 November 2008, pendirian bank tersebut disepakati oleh negara anggotanya yaitu negara Kuba, Bolivia, Nikaragua, Saint Vincent \& Grenadines, Dominika, dan Venezuela (SELA, 2014). Penetapan bank tersebut sebagai bank sentral bagi negara anggota ALBA juga menjadi momentum bagi pengusulan mata uang SUCRE.

Pembentukan SUCRE ini dipelopori oleh Hugo Chavez sebagai alat transaksi dalam perdagangan regional antar negara anggota ALBA. Sebagai tindak lanjut, KTT ALBA ke VII pada 16 Oktober 2009 di Bolivia menjadi momen penetapan SUCRE sebagai alat transaksi perdagangan diantara anggota ALBA dengan Bolivia, Kuba, Ekuador, Nikaragua, dan Venezuela yang turut meratifikasi kesepakatan tersebut (SELA, 2014). ALBA menganggap penting penggunaan SUCRE bagi anggotanya karena dapat memberikan manfaat yaitu menguatkan nilai mata uang nasional yang tidak terepresentasikan apabila ALBA tetap menggantungkan pada dolar AS. Penggunaan SUCRE akan menghilangkan tambahan biaya yang selama ini tidak terjadi apabila menggunakan dolar AS sehingga barang impor memiliki harga tidak terlalu tinggi.

Walaupun SUCRE memberikan berbagai manfaat bagi para anggotanya, namun dari 8 negara anggotanya hanya 5 negara yang telah melakukan penandatanganan Framework. Agreement for The Creation of SUCRE. Sedangkan 3 negara lainnya yaitu Dominika, Saint Vincent \& Grenadines, dan Antigua \& Barbuda tidak tercantum sebagai negara yang ikut serta dalam framework ini. PM Dominika Roosevelt Skerrit setelah pulang dari ALBA Summit ke-XI yang diselenggarakan di Venezuela mengatakan bahwa negara seperti Dominika, St. Vincent \& Grenadines, dan Antigua \& Barbuda tidak dapat mengikuti kerangka kerja sama tersebut (Dominica News Online, 2012a). Pernyataan tersebut menunjukkan bahwa PM Dominika, Roosevelt Skerrit tidak akan menandatangani framework mata uang baru SUCRE.

Membahas mengenai dinamika implementasi mata uang SUCRE, terdapat beberapa studi terdahulu seperti yang ditulis oleh Antulio Rosales dan Ricardo Molero. Studi tersebut menjelaskan bahwa peran SUCRE sebagian besar yaitu mempromosikan integrasi moneter yang berdasarkan solidaritas dan saling melengkapi, bukan atas dasar persaingan. Namun tantangan utama yang dihadapi yaitu membuat SUCRE agar dapat menjadi mata uang yang dipercaya sehingga dapat meningkatkan perdagangan namun hingga saat ini efeknya tidak signifikan. Sehingga untuk meningkatkan eksistensi mata uang tersebut, dibutuhkan upaya untuk mempromosikan SUCRE 
sebagai mata uang utama di kawasan, dengan tujuan utama melalui UNASUR (Rosales \& Molerosimarro, 2015).

Selain itu, dampak mengenai penerapan mata uang tersebut dalam skala negara dapat dilihat melalui penelitian yang ditulis oleh Basri Hassanudin Latief. Penjelasan mengenai ketidakberhasilan ALBA dalam mempromosikan SUCRE di tataran regional juga berdampak pada keefektifan mata uang tersebut pada ekonomi Venezuela. Diketahui mata uang tersebut tidak memberikan kontribusi yang signifikan pada perekonomian negara tersebut karena ALBA sendiri tidak dapat meyakinkan negara-negara Amerika Latin lainnya untuk menggunakan SUCRE. Selain itu, adanya oposisi dari AS mengenai adanya mata uang regional tersebut juga berdampak besar pada persepsi negara di kawasan dalam memandang inisiasi tersebut (Latief, 2015).

Hal tersebut berdampak pada ketidakikutsertaan negara-negara seperti Dominika, St. Vincent \& Grenadines, dan Antigua \& Barbuda dalam inisiasi mata uang Sucre tersebut sesuai dengan artikel yang ditulis oleh Rusmah Wardani (Wardani, 2019). Terdapat beberapa faktor yang melandasi ketidakikutsertaan ketiga negara tersebut, diantaranya adalah: 1) Pendapatan nasional ketiga negara tersebut dapat dikatakan relatif rendah sehingga tidak memiliki cadangan uang nasional yang cukup, 2) Keharusan ketiga negara tersebut untuk menyerahkan kedaulatannya kepada Bank Sentral Karibia Timur, dan 3) Kepentingan ketiga negara tersebut untuk mempertahankan stalitas moneter mereka, meliha pendapatan perkapita mereka yang rendah. Selain itu penggunaan mata uang Sucre juga menjadi hambatan bagi transaksi perdagangan ketiga negara tersebut karena adanya pembatasan penggunaan dolar AS yang selama ini menjadi mata uang transaksi utama mereka. Berdasarkan studi literatur diatas, artikel ini menyentuh kebaruan kajian pada analisa mengenai kebijakan penolakan Sucre yang berfokus pada Dominika dengan menimbang faktor internal dan eksternal negara tersebut.

Melihat hal diatas, adanya keputusan ketidakikutsertaan Dominika ini dianggap menarik untuk dikaji karena Dominika merupakan negara termiskin diantara negara anggota lainnya. Dimana sebelumnya negara tersebut memutuskan bergabung dalam ALBA karena menganggap bahwa organisasi tersebut menjadi alternatif untuk membantu pembangunan di Dominika melalui bantuan insentif yang diberikan. Namun ketika ALBA memberikan SUCRE sebagai alternatif baru untuk dapat mengurangi ketergantungan dalam penggunaan dolar AS, lembaga keuangan IMF dan World Bank, Dominika menolak justru untuk bergabung. Maka dari itu, tulisan ini bertujuan untuk menjelaskan mengapa Dominika membuat kebijakan untuk menolak mata uang SUCRE.

Agar dapat melihat keputusan Dominika sebagai negara nggota ALBA dalam menolak SUCRE, penulis menggunakan teori The Formulation of Foreign Policy Objectives yang berargumen dasar bahwa dalam merumuskan tujuan kebijakan luar negeri suatu negara dapat diidentifikasi berdasarkan faktor internal yang meliputi kebutuhan ekonomi, kebutuhan poltik, citra negara, dan kapabilitas negara. Sedangkan faktor eksternal yang meliputi adanya kesempatan dan tantangan dalam perdagangan, peperangan dan kehancuran ekonomi, dan adanya suatu momentum yang dapat meningkatkan prestise negara. Identifikasi tersebut dianggap penting agar keputusan kebijakan luar negeri sesuai dengan tujuan yang ingin dicapai oleh negara. Sehingga dengan mengidentifikasi negara dapat menentukan batasan usaha yang dapat dilakukan dalam mencapai tujuan negaranya melalui penetapan kebijakan luar negeri yang baik dan teratur (Little \& Smith, 2005). 


\section{Metode}

Adapun jenis penelitian dalam artikel ini berjenis eksplanatif kualitatif. Penelitian eksplanatif merupakan penelitian yang bertujuan untuk menerangkan, menguji hipotesis dari variabel-variabel penelitian, sehingga fokus penelitian ini adalah analisis hubungan-hubungan antara variabel (Singarimbun \& Effendi, 1981). Penelitian kualitatif merupakan penelitian yang bertujuan untuk memahami fenomena tentang apa yang didalami oleh subyek penelitian misalnya persepsi, motivasi, dan tindakan lainnya secara holisitik dengan deskripsi melalui kata-kata ataupun bahasa dengan menggunakan berbagai metode alamiah (Moleong, 2018). Metode pengumpulan data pada artikel ini menggunakan studi pustaka dan penelusuran data online yang dihimpun oleh berbagai sumber data sekunder seperti buku, jurnal, artikel daring, koran, dan majalah.

\section{Hasil dan Pembahasan}

\section{Keanggotaan Dominika dalam ALBA}

Salah satu alasan bergabungnya Dominika dalam organisasi regional ALBA dapat dilihat melalui faktor insekuritas geografis yang berimbas pada rentannya keadaan ekonomi serta sosial jika terjadi bencana. Keadaan geografi Dominika bergunung, memiliki intensitas curah hujan yang tinggi, dan berada pada paling utara dari Kepulauan Windward yang menyebabkan Dominika masuk kedalam Atlantic Hurricane Belt (ACAPS, 2018). Hal tersebut membuat Dominika rentan terhadap berbagai bencana alam, yang paling sering ialah dilanda badai tropis dan angin topan. Badai seringkala melanda di Dominika, terhitung setelah Dominika mendapatkan kemerdekaannya hingga rentan waktu 2011. Sebanyak 9 badai telah melanda Dominika, dan yang paling memiliki dampak adalah terjadinya Badai David pada tahun 1979.

Badai David terjadi pada 29 Agustus 1979, ketika hujan deras datang diikuti dengan angin yang bergerak dengan kecepatan 150 mil per jam, kemudian menghantam Dominika dan berlangsung selama enam jam. Peristiwa tersebut menyebabkan tanah longsor besar, berbagai infrastruktur hancur seperti jalan dan jembatan, komunikasi ke dunia luar terputus. Daerah yang mengalami kerusakan paling parah yaitu di daerah barat daya Dominika dan ibu kota Rosseau. Diperkirakan 37 orang meninggal dan 5.000 orang terluka. Perdana Menteri Seraphin menyatakan dalam sebuah wawancara bahwa bantuan dana masuk dari IMF, International Red Cross (IRC), Gerakan Non-Blok (GNB), Organisations of American States (OAS), Uni Eropa, dan Caribbean Community (CC) dengan total bantuan dana sekitar US \$37 juta (Dominica News Online, 2012b).

Karakteristik geografis Dominika tersebut memberikan dampak terhadap karakteristik ekonomi Dominika. Dominika merupakan negara yang memiliki total populasi sekitar 71.440 jiwa pada tahun 2010 dengan total PDB per kapita sebesar US \$ 6,670. Berdasarkan tabel 1 aktifitas ekonomi yang mampu memberikan berkontribusi besar terhadap PDB ialah sektor perdagangan, transportasi dan komunikasi serta agrikultur. Sektor transportasi dan komunikasi menduduki sektor yang paling tinggi dalam menyumbang PDB Dominika yaitu sekitar 13\%, selanjutnya sektor perdagangan mampu menyumbang sekitar 11\% terhadap PDB Dominika, kemudian diikuti oleh sektor agrikultur sebesar 9\%. Berbeda halnya dengan sektor manufaktur, sektor ini memberikan kontribusi yang relatif kecil terhadap PDB Dominika yaitu berada di kisaran 3\% (Organization of American States, 2012). 
Tabel 1. Kontribusi Aktifitas Ekonomi Terhadap PDB Dominika (*Dalam Persen)

\begin{tabular}{lcccc}
\hline \multicolumn{1}{c}{ Aktifitas Ekonomi } & $\mathbf{2 0 0 7}$ & $\mathbf{2 0 0 8}$ & $\mathbf{2 0 0 9}$ & $\mathbf{2 0 1 0}$ \\
\hline Transportasi dan Komunikasi & 13,4 & 13,4 & 12,7 & 12,5 \\
\hline Perdagangan & 10,5 & 11,2 & 11,9 & 11,8 \\
\hline Hotel dan Restauran & 1,7 & 1,6 & 1,5 & 1,5 \\
\hline Manufaktur & 3,8 & 3,1 & 3,1 & 3 \\
\hline Agrikultur & 8,9 & 9,4 & 9,7 & 8,8 \\
\hline Tanaman Panen & 7,5 & 8,3 & 8,6 & 7,7 \\
\hline Peternakan & 1,1 & 0,9 & 0,9 & 0,9 \\
\hline Kehutanan & 0,3 & 0,3 & 0,3 & 0,3 \\
\hline
\end{tabular}

Sumber: Organization of American States (2012)

Penduduk Dominika yang sebagian besar bekerja di sektor agrikultur menunjukkan bahwa sebagian besar kegiatan ekonomi masyarakat di Dominika berada pada sektor tersebut. Sektor agrikultur memainkan peran penting dalam kegiatan ekonomi Dominika, sektor ini mampu mempekerjakan satu pertiga tenaga kerja dari total populasi serta menjadi salah satu pendapatan devisa. Berdasarkan tabel 2.1 dapat diketahui bahwa tanaman panen memiliki presentase paling tinggi dalam memberikan kontribusinya terhadap PDB Dominika dibandingkan dengan peternakan dan kehutanan. Sektor agrikultur yang mampu menjadi kegiatan utama dalam ekonomi Dominika memiliki diversifikasi produksi. Pada sektor tanaman panen pisang merupakan komoditas tanaman panen yang paling banyak di produksi, yang kemudian diikuti oleh sayuran dan buah-buahan.

Karakteristik ekonomi Dominika juga memiliki keterikatan terhadap karakteristik geografis Dominica sebagai negara yang masuk dalam Atlantic Huricane Belt. Dominika yang sering dilanda bencana alam seperti badai tropis dan angin topan mengakibatkan terjadinya kerusakan parah pada berbagai infrastruktur Dominika, sehingga dapat mengahambat laju kegiatan ekonomi. Infrastruktur yang rusak membuat aktifitas ekonomi yang mampu meberikan kontribusi besar seperti transportasi berhenti beroperasi. Kerusakan juga terjadi pada tanaman panen yang selama ini menjadi basis ekonomi negara. Hal tersebut membuat Dominika melakukan pinjaman luar negeri untuk dapat melakukan rekonstruksi dan rehabilitasi terhadap proyek infrastruktur publik yang membuat kenaikan jumlah hutang. Dominika mengalami kekacauan ekonomi karena berbagai infrastruktur dalam mendukung kegiatan ekonomi mengalami kerusakan.

Dominika yang sadar akan kondisi negaranya, dimana memiliki wilayah yang kecil ditambah dengan kemampuan ekonomi dan sumber daya terbatas, membuat Dominika mencari sebuah keuntungan lain dari berbagai organisasi internasional maupun regional. Dominika mempertimbangkan dengan serius untuk bergabung dalam sebuah aliansi yang ditawarkan oleh Venezuela yaitu ALBA. Dikarenakan itu merupakan sebuah peluang baru dan alternatif baru untuk dapat mencapai tujuan negara. Akhirnya, Dominika memutuskan untuk bergabung dalam ALBA. Dominika bergabung dalam ALBA untuk memperoleh peluang dalam mencapai tujuannya yaitu menjaga stabilitas moneter dengan meningkatkan infrastruktur sosial. Tercatat bahwa dalam 
proyek sosial, ALBA tercatat memberikan bantuan ke Dominika sebesar $\$ 119$ juta dolar Karibia Timur untuk 26 proyek di perumahan, infrastruktur, keamanan dan pertanian yang dapat menguntungkan lebih dari 1.000 keluarga atau sekitar 34.000 individu, angka yang terakhir menunjukkan bahwa bantuan ALBA tersebut dapat membantu kira-kira 45 persen dari populasi nasional yang telah mendapat keuntungan (Edmonds, 2012). Bantuan sebesar \$119 juta dolar Karibia Timur yang diberikan ALBA kepada Dominika tersebut dialokasikan ke berbagai proyek sosial seperti di tabel 2 .

Tabel 2. Penyebaran Alokasi Dana ALBA Dalam Proyek Dominika

\begin{tabular}{|c|c|c|c|}
\hline Proyek Sosial & $\begin{array}{l}\text { Jumlah } \\
\text { Proyek }\end{array}$ & $\begin{array}{l}\text { Dukungan Dana } \\
\text { (EC Dalam C\$) }\end{array}$ & Keuntungan \\
\hline Infrastruktur & 7 & 57.25 & $\begin{array}{l}\text { Akses keamanan transportasi, } \\
\text { Pembenahan bandara sebagai akses } \\
\text { udara internasional, } 26.000 \text { penerima } \\
\text { manfaat }\end{array}$ \\
\hline Perumahan & 10 & 41.3 & $\begin{array}{l}\text { Sebanyak } 1.011 \text { kleuarga dengan } \\
\text { penghasilan menengah kebawah } \\
\text { dapat memiliki rumah }\end{array}$ \\
\hline Pariwisata dan UKM & 1 & 14.0 & $\begin{array}{l}\text { Menguntungkan para pengrajin dan } \\
\text { para pengusaha kecil }\end{array}$ \\
\hline Keamanan & 6 & 9.0 & $\begin{array}{l}8.500 \text { orang secara langsung } \\
\text { meningkatkan keamanan nasional }\end{array}$ \\
\hline $\begin{array}{l}\text { Bantuan untuk } \\
\text { masyarakat miskin }\end{array}$ & 1 & 2.5 & \\
\hline Peternakan & 1 & - & \\
\hline Total & 26 & 119.358 & \\
\hline
\end{tabular}

Sumber: NACLA (2012)

Proyek-proyek ini merupakan elemen utama dalam strategi pertumbuhan dan perlindungan sosial oleh pemerintah yang bertujuan untuk mencapai pengurangan kemiskinan dan perlindungan sosial melalui pertumbuhan yang pro-masyarakat miskin. Berdasarkan Country Poverty Assessment pemerintah Dominika melaporkan bahwa tingkat kemiskinan telah turun dari 39 persen pada tahun 2003 menjadi 28,8 persen pada tahun 2009 (Dominica News Online, 2012b). Pengurangan kemiskinan ini dapat meningkatkan kesejahteraan sosial di Dominika yang akan memberikan dampak pada kestabilan ekonomi.

\section{SUCRE Sebagai Mata Uang Regional ALBA}

SUCRE dibentuk dalam sebuah proposal Framework. Agreement for the Creation of SUCRE yang disetujui oleh negara-negara anggota ALBA pada KTT ALBA VII yang diadakan di Cumana pada 16 April 2009. Berdasarkan perjanjian konstitutifnya yang tercantum dalam Framework Agreement for The Creation of SUCRE, pada pasal 1 menjelaskan bahwa SUCRE didefinisikan sebagai sebuah kerjasama ekonomi dan keuangan, integrasi dan komplementaritas yang disepakati untuk dapat mempromosikan pembangunan integral di kawasan Amerika Latin dan Karibia serta 
mengkoordinasikan sistem penggunaan SUCRE dengan pedoman yang ditetapkan oleh ALBATCP Economic Complementarity Ministerial Council (SELA, 2013).

Pada 16 Oktober 2009 dengan bertempat di Bolivia, negara-negara ALBA melakukan pertemuan untuk menandatangani kesepakatan mengenai SUCRE. Pada 27 Januari 2010 manghasilkan kesepakatan mulai digunakannya SUCRE sebagai transaksi perdagangan diantara negara anggota ALBA-TCP (ALBA, 2014). Perjanjian ini tidak ditandatangani oleh semua anggota ALBA, hanya lima negara anggota ALBA yang sepakat untuk bergabung dalam SUCRE yaitu Bolivia, Kuba, Ekuador, Nikaragua, dan Venezuela. Namun tiga negara Karibia yang ikut serta dalam ALBA telah memutuskan untuk tidak bergabung dalam SUCRE, salah satunya Dominika. Setelah itu perjanjian tersebut secara progresif diratifikasi oleh parlemen nasional dan sistem mulai beroperasi secara bersamaan.

SUCRE dirancang sebagai sebuah mekanisme pembayaran internasional dalam operasi perdagangan yang mengakibatkan adanya timbal balik yang terjadi diantara negara anggota ALBA. Sistem ini didasarkan pada penggunaan mata uang virtual. Hal tersebut berarti bahwa pembayaran dalam melakukan transaksi ekspor dan impor dilakukan menggunakan mata uang lokal yang kemudian diverifikasi oleh bank-bank sentral yang telah terdaftar. Hal tersebut membuat SUCRE dapat saling memberi kompensasi satu sama lain diantara negara-negara anggota dengan menggunakan mata uang mereka sendiri sampai batas yang telah ditentukan. Penggunaan mata uang lokal ini dapat mengurangi biaya transaksi yang selama ini dikenakan ketika konversi mata uang. Penggunaan mata uang lokal memberi penghematan biaya konversi 5\%. Hal ini menjadi sebuah kesempatan bagi negara anggota untuk dapat mendorong perdagangan intra-regional dengan meningkatkan daya saing produsen antar negara anggota serta memberikan ruang bagi bank sentral lebih banyak untuk melakukan manuver dengan cadangan devisa dan mengurangi kerentanan terhadap penyimpangan dolar AS.

\section{Bagan 1. Sistem Alur Pembayaran Dalam SUCRE}

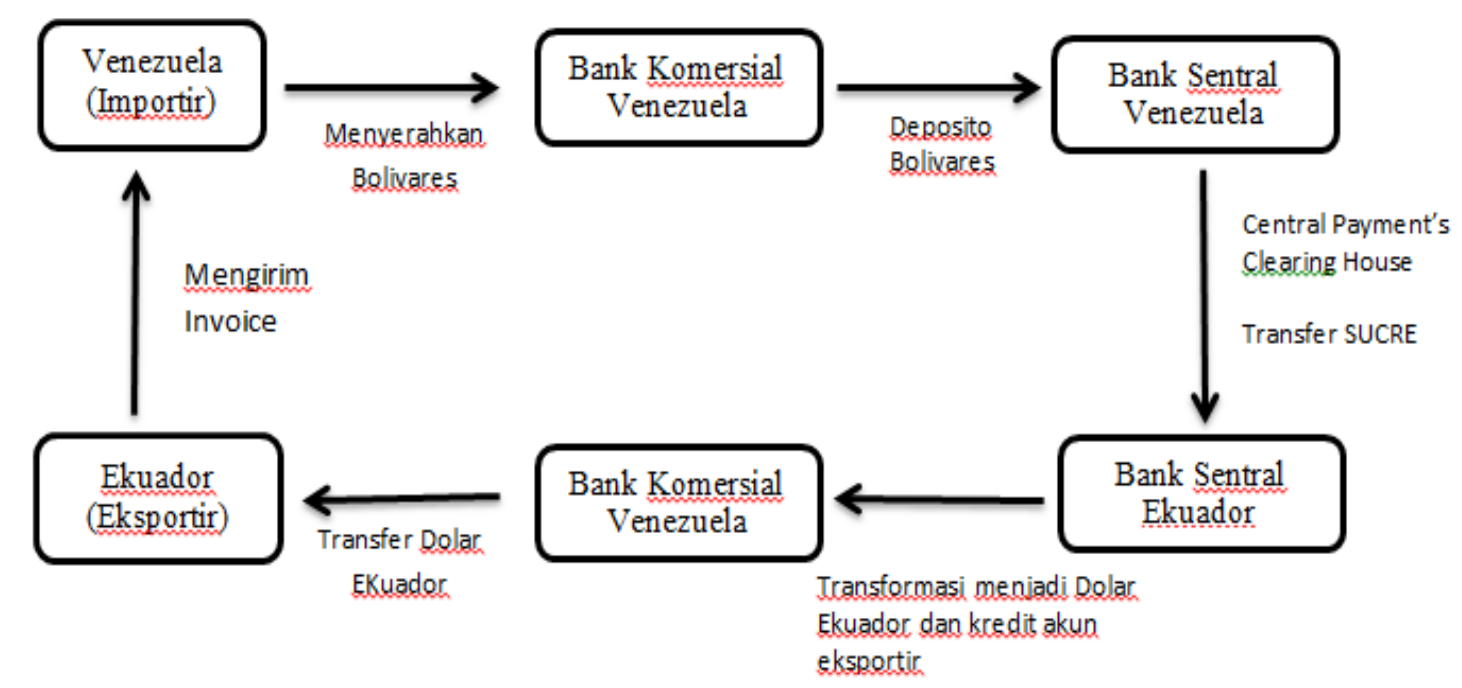

Sumber: diolah penulis 
Fitur utama dari proposal SUCRE adalah pembuatan unit akun regional SUCRE untuk mengganti dolar dalam transaksi. Penggunaannya terbatas pada operasi faktur dalam pembayaran perdagangan intra-regional hanya pada tingkat bank sentral. SUCRE dirancang untuk menjadi unit umum dengan nilainya yang berasal dari mata uang negara anggotanya yang ditimbang berdasarkan ekonomi relatifnya (Fritz \& Mühlich, 2014). Berdasarkan Tabel 3 mekanisme dalam penggunaan SUCRE ini dapat dilihat dari cara transaksi diantara Venezuela dan Ekuador sebagai negara pertama yang mengimplementasikan SUCRE. Sebuah perusahaan di Ekuador sebagai negara eksportir dan negara Venezuela sebagai negara importir setuju untuk melakukan transaksi menggunakan mata uang SUCRE dalam pembayarannya yang secara mekanisme dilakukan melalui bank komersial yang telah disepakati. Kemudian negara eksportir Ekuador mengirimkan pihak importir yang berasal dari Venezuela invoice dalam mata uang dolar AS, yang merupakan mata uang nasional Ekuador.

Perusahaan Venezuela kemudian mengiriman invoice kepada bank komersial di Venezuela yang telah disepakati. Kemudian mata uang bolivar di depositokan oleh Bank sentral komersial tersebut ke bank sentral Venezuela, menyerahkan bolivar. Bank sentral kemudian melakukan pencatatan transaksi negara pihak impor. Bank Sentral negara pihak importir melakukan konversi dana yang diterima dalam mata uang bolivar ke SUCRE. Bank sentral mencatat transaksi di Sistem Informasi dari SUCRE yang mengakibatkan alokasi SUCRE dan dikreditkan ke rekening bank sentral eksportir Ekuador. Bank sentral Ekuador mendapatkan kredit SUCRE yang kemudian di konversi dari jumlah transaksi SUCRE ke mata uang lokal dolar.

Penyederhanaan administrasi dalam transaksi perdagangan internasional ini membuat harga komoditas impor yang tiba di masyarakat tidak mengalami peningkatan yang tajam. Berbeda ketika menggunakan dolar sebagai alat tukar yang akhirnya membuat harga barang tiba di masyarakat dengan harga yang mahal. Hal tersebut membuat SUCRE lebih dipilih oleh beberapa negara anggota ALBA. Adanya badan operasional dan sistem pembayaran yang telah dirancang membuat SUCRE sebagai mata uang yang jelas dalam melakukan transaksi, serta berbagai badan operasional membuat SUCRE memiliki berbagai hukum dan kebijakan pengaturan yang dapat menjadi sebuah lembaga pengawas dalam penggunaan SUCRE. Sehingga sistem operasional dalam SUCRE diharapkan dapat berjalan lancar dan memberikan manfaat baik secara ekonomis maupun utilitas. Bahkan SUCRE dapat berekspansi di luar negara anggota ALBA apabila SUCRE menyediakan proliferasi dalam pertukaran SUCRE. Sehingga dapat memberikan jaminan yang lebih besar bagi negara yang berpartisipasi.

\section{Faktor Pengaruh Keputusan Dominika}

Pertama, SUCRE bertentangan dengan keanggotaan Dominika di OECS. Dominika mengikuti berbagai keanggotaan dalam sebuah organisasi regional maupun sub-regional. Dominika lebih dahulu bergabung sebagai anggota dari organisasi di wilayah Karibia Timur yaitu Organisation of Eastern Caribbean State (OECS) pada tanggal 18 Juni 1981 sebelum bergabung dalam organisasi ALBA. Dominika bergabung dalam OECS setelah melakukan penandatanganan terhadap Treaty of Basseterre bersama dengan 6 negara lainnya dengan status keanggotaan penuh (OECS, 2017). Perjanjian tersebut merupakan kumpulan dari kehendak negara-negara Karibia Timur menciptakan sebuah kesepakatan yang tertuang dalam sebuah instrumen yuridik mengenai kewajiban dan hak yang harus dilakukan oleh negara anggota. Hal tersebut membuat Dominika 
harus mengikuti seluruh keanggotaan dan kegiatan dari organisasi tersebut dengan berbagai hak dan kewajibannya.

Ketika ALBA melakukan ekspansi ke wilayah Karibia, Dominika meninjau dari perjanjian yang telah disepakati di perjanjian Basseterre sebelum memutuskan untuk bergabung. Dalam perjanjian tersebut dijelaskan pada pasal 20 yang membahas tentang hubungan dengan organisasi lain yang intinya ialah bahwa sebuah organisasi harus mampu membangun hubungan kerja yang efektif dengan organisasi internasional, organisasi regional dan pemerintah dari negara lainnya yang dapat mencapai tujuannya (OECS, 2010). Dominika memutuskan bergabung dalam ALBA untuk memperoleh peluang dalam mencapai tujuannya yaitu menjaga stabilitas moneter dengan meningkatkan infrastruktur sosial selain itu juga tidak melanggar ketentuan yang ada di OECS.

Namun ketika ALBA menawarkan peluang baru untuk mengurangi ketergantungan terhadap dolar Amerika Serikat dengan membuat sebuah regional currency yaitu SUCRE. Dominika dengan tegas menolak penggunaan SUCRE dalam melakukan transaksi di antara negara anggota ALBA. Hal ini dilakukan karena telah menyangkut kebijakan moneternya, sehingga keputusan dominika untuk menyetujui atau menolak dalam penggunaan SUCRE juga harus ditinjau dari Treaty Bassetrre di OECS. Berdasarkan pengaturan kebijakan moneter di OECS pada pasal 14 mengungkapkan bahwa "The monetary policy of the Economic Union shall be executed by the Monetary Council through the Eastern Caribbean Central Bank under the terms and conditions of the Eastern Caribbean Central Bank Agreement' (OECS, 2010). Perjanjian tersebut dengan jelas menerangkan bahwa kebijakan moneter negara anggota OECS dilaksanakan oleh Dewan Moneter melalui Bank Sentral Karibia Timur di bawah syarat dan ketentuan Perjanjian Bank Sentral Karibia Timur. Sehingga apabila Dominika harus menyetujui kerangka kerjasama tersebut maka akan melanggar perjanjian Basseterre yang ada di OECS.

Kebijakan Dominika untuk memilih berkomitmen bertahan di OECS karena menganggap bahwa OECS memberikan pengaruh besar bagi kondisi ekonomi dan politik di Dominika. Dikarenakan negara kecil dan rentan seperti Dominika lebih mampu berfungsi di pasar global melalui keanggotaan dan keterlibatan dalam gerakan integrasi ekonomi regional seperti OECS. Dikarenakan menjalin kerjasama dengan anggota di kawasan yang memiliki berbagi atribut yang sama seperti memiliki budaya, bahasa, sistem hukum, mata uang dan ekonomi, serta sistem pendidikan yang seragam lebih mudah untuk diarahakan dalam mencapai tujuan melalui sebuah organisasi seperti OECS.

Hal tersebut membuat Dominika melepaskan sebagian kedaulatannya untuk mengadopsi dan mematuhi berbagai peraturan organisasi guna mencapai tujuan dan sasarannya. Walaupun hal tersebut membuat Dominika kehilangan kemampuan eksklusif yang biasa dimiliki oleh negara untuk terlibat dalam berbagai transaksi regional dan inetrnasional karena melimpahkan wewenang dibidang perwakilan diplomatk kepada OECS. Fakta yang tak terelakkan adalah bahwa Dominika dan negara-negara anggota OECS dihadapkan oleh perubahan iklim global yang cepat seperti adanya ekspansi dalam perdagangan bebas. Integrasi ini sangat penting jika negara ingin bertahan hidup dalam ekonomi global ini. Meskipun Dominika mempertahankan keanggotaan dalam berbagai gerakan integrasi regional lainnya, sumber daya keuangan yang langka membatasi keterlibatan penuhnya. Lebih lanjut, keanggotaan dalam gerakan-gerakan integrasi yang lebih besar ini telah menyebabkan konflik yang tidak dapat dihindari dengan negara-negara anggota lainnya. 
Kedua, cadangan devisa Dominika tidak mampu memenuhi persyaratan untuk menerapkan SUCRE. Persyaratan untuk dapat menerapkan SUCRE maka negara anggota ALBA harus bergabung dalam Bank of ALBA yang merupakan bank sentral yang menjadi pengawas dalam pengoperasian SUCRE. Negara anggota dapat bergabung dalam Bank of ALBA dengan memberikan 1\% dari cadangan internasionalnya kepada ALBA. Negara-negara anggota ALBA menyerahkan cadangan devisa mereka sebesar 1\% ke Bank of ALBA agar bank ini bisa beroperasi dan menggunakan dana tersebut untuk membiayai program-program ALBA, salah satunya adalah SUCRE. Cadangan devisa ialah aset-aset eksternal yang telah tersedia untuk dikendalikan oleh otoritas moneter dan dapat digunakan setiap waktu dalam memenuhi neraca pembayaran, serta dalam rangka stabilitas moneter dengan melakukan intervensi di pasar valuta asing (imf.org). Dominika memutuskan untuk tidak bergabung dalam Bank of ALBA. Keputusan Dominika tersebut ditinjau dari cadangan internasional yang dimilikinya.

Berdasarkan tabel 4 dapat diketahui bahwa Dominika memiliki cadangan internasional yang paling rendah diantara negara anggota OECS lainnya. Sehingga tidak ada satupun negara anggota OECS yang bergabung dalam ALBA memiliki total cadangan yang tinggi sehingga mampu memberikan 1\% cadangan internasionalnya kepada Bank of ALBA. Begitupula dengan Dominika yang tidak memiliki cadangan devisa membuatnya tidak mampu memberikan 1\% cadangan yang diminta. Disisi lain adanya kekacauan perekonomian Dominika ini membuat pertimbangan bahwa dana cadangan yang telah ada lebih baik Dominika pergunakan untuk rekonstruksi infrastruktur dan pemulihan situasi yang cepat sehingga dapat memberikan surplus yang dapat meningkatkan pertumbuhan ekonomi dominika.

Tabel 3. Perbandingan Cadangan Devisa Negara Anggota ALBA 2008 (Dalam Ribuan Dolar)

\begin{tabular}{c|c}
\hline Negara & Total Reserves \\
\hline Venezuela & $29,665.46$ \\
\hline Kuba & 144,018 \\
\hline Bolivia & $2,622.49$ \\
\hline Ekuador & $2,622.49$ \\
\hline Nikaragua & $1,798.98$ \\
\hline Antigua and Barbuda & 136.60 \\
\hline St.Vincent and Grenadines & 112.70 \\
\hline Dominika & 76.10 \\
\hline
\end{tabular}

\section{Sumber: World Bank (2008) (diolah penulis)}

Menipisnya persediaan cadangan devisa negara Dominika ini dapat menimbulkan tingginya tingkat kerentanan ekonomi negara yang bersangkutan. Posisi cadangan devisa suatu negara biasanya dinyatakan aman apabila mencukupi kebutuhan impor untuk jangka waktu setidaknya tiga bulan. Jika cadangan devisa yang dimiliki tidak mencukupi kebutuhan untuk tiga bulan impor, maka hal itu dianggap rawan. Sehingga untuk dapat menstabilkan moneternya dari berbagai guncangan eksternal seperti krisis ekonomi dan bencana alam yang melanda. Dominika 
memilih menolak integrasi moneter SUCRE dikarenakan lebih baik cadangan devisa yang telah ada dilakukan untuk melakukan pembangunan nasional dan pemulihan infrastruktur. Disisi lain PM Skerrit menjelaskan lebih lanjut dalam konfrensinya kepada media bahwa apabila Dominika bergabung dalam pengaturan keuangan di Bank of $A L B A$ maka Dominika harus memberikan kontribusi, besarnya kontribusi negara anggota yang harus diberikan kepada Bank of ALBA diukur berdasarkan penilaian bank terhadap perekonomian salah satunya melalui cadangan dan GDP.

Berdasarkan Grafik 4. Dominika memiliki GDP yang paling rendah diantara negara anggota OECS lainnya yang tergabung dalam ALBA. Sehingga kemampuan perekonomian dominika tidak dapat memberikan kontribusi besar terhadap Bank of ALBA. Selain itu keadaan ekonomi yang rendah tersebut tak memungkinkan Dominika untuk dapat memenuhi kontribusinya karena untuk memenuhi kebutuhuan ekonomi nasionalnya saja Dominika masih membutuhkan bantuan dari berbagai pihak. Hal yang terjadi apabila Dominika memaksakan bergabung dalam pengaturan keuangan Bank of ALBA akan membuat Dominika tidak memiliki cukup ruang untuk dapat menempatkan Dominika pada posisi dimana untuk dapat mempengaruhi pengambilan kebijakan yang dapat mencapai kepentingan bagi Dominika.

Grafik 1. Perbandingan GDP Negara Anggota OECS yang tergabung dalam ALBA 2006-2010 (Dalam Juta Dolar)

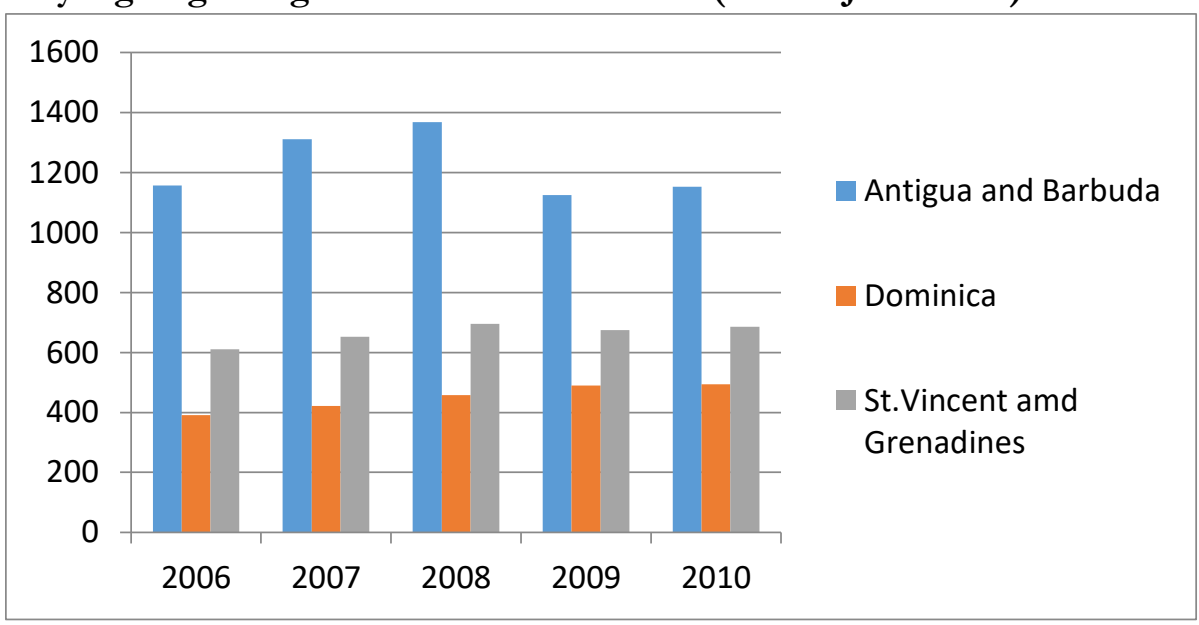

Sumber: (World Bank 2020) (diolah penulis)

Ketiga, Dominika tidak memiliki kapasitas untuk dapat mempengaruhi kebijakan di SUCRE. Sebagai negara anggota OECS dalam Protocol Economic Union pasal 15 menyatakan bahwa Kebijakan moneter anggota dalam perserikatan ekonomi OECS akan dilaksanakan oleh Dewan Moneter melalui Bank Sentral Karibia Timur di bawah syarat dan ketentuan Perjanjian Bank Sentral Karibia Timur (oecs.org). Dominika dalam keanggotaannya di ECCB memiliki kedudukan sebagai dewan moneter yang memiliki tugas untuk melakukan perencanaan yang kemudian dilanjutkan dengan mengkordinasi pelaksanaan. Dominika memiliki pilihan untuk tetap bertahan dalam pengaturan ECCB atau keluar dari pengaturan ECCB dan bergabung dalam ALBA.

Dominika kemudian memutuskan untuk tetap bertahan dalam pengaturan ECCB. Hal ini berdasarkan pertimbangan bahwa latar belakang ekonomi Dominika yang rendah membuat negara tersebut tak mampu memiliki ruang gerak banyak di organisasi maupun aliansi lainnya dalam mempengaruhi kebijakan yang dapat memihak serta memberikan keuntungan kepada negaranya. 
Seperti halnya keikutsertaan Dominika di SUCRE yang akan membuat Dominika dikeluarkan menjadi anggota dewan moneter. Selanjutnya Dominika memiliki ruang gerak yang terbatas dalam mempengaruhi sebuah kebijakan yang dapat memihak pada kepentingan Dominika. Sedangkan keanggotaan Dominika di ECCB sebagai dewan moneter dapat merepresentasikan kepentingannya melalui negosiasi dalam pengambilan kebijakan di ECCB untuk dapat meningkatkan perekonomian Dominika. Karena melalui kebijakan moneter inilah permintaan suatu negara dapat disokong secara optimal dalam mencapai kepentingan nasionalnya.

Keempat, penerapan SUCRE terbatas yang berdampak pada pangsa pasar Dominika. Dominika menganggap bahwa SUCRE hanyalah sebuah instrumen dalam melakukan pembayaran yang dilakukan antar negara anggota ALBA. Transaksi penggunaan SUCRE hanya dapat dilakukan oleh negara antar anggota ALBA. Negara angota ALBA yang menerapkan SUCRE, makan akan melakukan transaksi perdagangan dengan menggunakan mata uang nasional. Sehingga apabila transaksi dengan menggunakan SUCRE tinggi, maka akan dapat menguatkan nilai mata uang nasional. Hal ini yang kemudian menjadi pertimbangan apabila Dominika bergabung dalam SUCRE ialah SUCRE akan memberikan manfaat apabila Dominika memiliki intensitas tinggi dalam penggunaan SUCRE.

Tabel 4. Negara Tujuan Ekspor dan Impor Negara Dominika Tahun 2007 (*Dalam USD)

\begin{tabular}{llllll}
\hline \multicolumn{3}{c}{ IMPOR } & \multicolumn{3}{c}{ EKSPOR } \\
\hline Rank & Country & Trade Value & Rank & Country & Trade Value
\end{tabular}

\begin{tabular}{llllll}
\hline 1 & United States & 69,856 & 1 & Jamaica & 7,373 \\
\hline 2 & Trinidad\&Tobago & 45,142 & 2 & Antigua\&Barbuda & 5,696 \\
\hline 3 & United Kingdom & 10,573 & 3 & United kingdom & 5,186 \\
\hline 4 & Japan & 8,115 & 4 & Frence & 3,568 \\
\hline 5 & China & 4,761 & 5 & Trinadad\&Tobago & 3,002 \\
\hline
\end{tabular}

Sumber: World Integrated Trade Solution (2007)

Kemudian Dominika meninjau kegiatan transaksi perdagangan yang selama ini dilakukan dengan negara anggota ALBA. Sehingga perlu diketahui negara tujuan utama ekspor Dominika untuk dapat menilai seberapa besar manfaat yang dapat diberikan oleh SUCRE. Mengetahui mitra dagang utama Dominika dianggap penting. Apabila mitra dagang utamanya merupakan negara anggota ALBA maka hal tersebut membuat SUCRE memberikan manfaat yang signifikan bagi Dominika dan memberikan sebuah kesempatan yang sangat menguntungkan. Berdasarkan tabel 5 diketahui bahwa negara yang menjadi tujuan utama ekspor kebanyakan berasal dari negara yang tergabung dalam OECS dan beberapa negara diluar Karibia seperti Perancis. Begitupula yang terjadi dengan negara Import terbesar di Dominika ialah kebanyakan dari negara anggota OECS dan beberapa negara diluar OECS seperti Amerika Serikat yang menjadi Importir utama bagi Dominika.

Berdasarkan data mitra dagang utama Dominika, ternyata intensitas perdagangan Dominika dengan negara anggota ALBA sangatlah minim. Penggunaan SUCRE yang terbatas hanya untuk negara anggota ALBA membuat pangsa pasar terbatas, sedangkan keinginan Dominika untuk dapat memperluas pasar membuatnya tidak sinkron dengan penggunaan SUCRE. Selain itu SUCRE sebagai mata uang regional tidak memiliki kepercayaan sebagai mata uang yang 
diakui di dunia internasional membuat SUCRE memiliki ruang gerak atitivitas ekonomi yang terbatas. Hal ini berpengaruh terhadap Dominika apabila menerapkan SUCRE, dimana tidak akan dapat meningkatkan efisiensi perdagangan negara tersebut melalui berkurangnya biaya transaksi nilai tukar. Hal ini membuat SUCRE menghadapi keterbatasan pada utilitas perdagangan yang rendah diantara para anggotanya. Sehingga ketidakikutsertaan Dominika dalam SUCRE tidak akan memberikan pengaruh yang signifikan terhadap perekonomian negara tesebut..

\section{Kesimpulan}

Penolakan Dominika terhadap penerapan SUCRE sebagai regional currency memiliki beberapa pertimbangan dengan melihat situasi politik dan ekonomi. Secara politik, Dominika merupakan negara yang menjadi anggota dari berbagai organisasi. Dimana Dominika terikat oleh pengaturan dari organisasi sebelumnya yaitu OECS dan menjaga komitmennya terhadap organisasi tersebut. Secara ekonomi kemampuan ekonomi yang rendah membuat Dominika memiliki keterbatasan ruang gerak apabila bergabung dalam SUCRE. Sehingga keputusan Dominika untuk tidak melakukan penerapan SUCRE dengan pertimbangan bahwa Dominika memilih untuk memenuhi kebutuhan dalam negerinya terlebih dahulu untuk dapat menciptakan kestabilan domestik dapat memaksimalkan kemampuannya dalam mencapai tujuan nasionalnya.

Pemberlakuan mata uang SUCRE memang memberikan keuntungan untuk dapat mengurangi dolar AS dalam melakukan perdagangan internasional, sehingga dapat memperkuat mata uang nasional. Namun yang menjadi pertimbangan ialah Dominika memiliki pangsa pasar utama di sesama negara nggota OECS dan beberapa di Uni Eropa dan Amerika Serikat. Sehingga manfaat SUCRE tidak dapat dirasakan oleh Dominika. Sehingga dalam fenomena penolakan negara Dominika terhadap penerapan SUCRE sebagai regional currency ALBA ditinjau dari tujuan dominika untuk dapat menjaga stabilitas moneternya berdasarkan faktor internal dan eksternal yang mempengaruhi, dapat diketahui bahwa SUCRE tidak memberikan manfaat yang signifikan untuk meningkatkan perekonomian Dominika.

\section{Referensi}

ACAPS. (2018). Dominica: the imapct of hurricane Maria. ACAPS Disaster Profile: Dominica, January, 1-13.

ALBA. (2014). What is the ALBA? ALBA Info. https://albainfo.org/what-is-the-alba/

Dominica News Online. (2012a). Dominica to stay away from the sucre. Dominica News Online. https://dominicanewsonline.com/news/homepage/news/business/dominica-to-stayaway-from-the-Sucre/

Dominica News Online. (2012b). Poverty in Dominica Disappointing but Reflects Global Situation - CDB President. Dominica News Online. https://dominicanewsonline.com/news/homepage/news/economydevelopment/poverty-in-dominica-disappointing-but-reflects-global-situation-cdbpresident/

Edmonds, K. (2012). ALBA Expands its Allies in the Caribbean (Part 1 of 2). NACLA. https://nacla.org/blog/2012/2/16/alba-expands-its-allies-caribbean-part-1-2

Fritz, B., \& Mühlich, L. (2014). Regional Monetary Co-operation in the Developing World Taking Stock. July, 1-59. 
Latief, B. H. (2015). Dampak Penerapan SUCRE Terbadap Perekonomian Venezuela. 1-122.

Little, R., \& Smith, M. (Eds.). (2005). Perspectives on World Politics. Routledge. https://doi.org/10.4324/9780203300527

Moleong, L. J. (2018). Metodologi Penelitian Kualitatif. PT Remaja Rosdakarya.

OECS. (2010). Revised treaty of Basseterre establishing the organisation of eastern caribbean states economic union. 1-43.

OECS. (2017). About OECS. OECS. https://oecs.org/en/homepage/about-us

Organization of American States. (2012). WT/TPR/S/299 - Dominica - 114 - ANNEX 2 DOMINICA.

Rosales, A., \& Molero-simarro, R. (2015). Discussion Paper no 31 Antulio Rosales Manuel Cerezal. August 2011.

SELA. (2013). ALBA-TCP as a mechanism for cooperation with a regional scope. October.

SELA. (2014). Evolution of the Bolivarian Alliance for the Peoples of our America - Peoples' Trade Treaty( ALBA-TCP ). November.

Singarimbun, M., \& Effendi, S. (1981). Metode Penelitian Survai. LP3ES.

Wardani, R. (2019). Alasan Dominica, St. Vincent and the Grenadines and Antigua and Barbuda Tidak Bergabung dalam Penyatuan Mata Uang Sucre. 5(4), 112-121.

World Bank. (2020). Total reserves (includes gold, current US\$). World Bank. https://data.worldbank.org/indicator/FI.RES.TOTL.CD?end=2020\&start=2020\&view= map

World Bank. (2008). Total reserves (includes gold, current US\$). World Bank. 